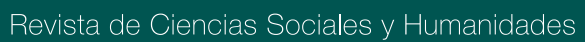

Número 10 / ABRIL, 2020 (12-24)

Luis Alberto Tuaza Castro

ltuaza@unach.edu.ec

Universidad Nacional de Chimborazo, Facultad de Ciencias de la Educación Humanas y Tecnologías, Carrera de

Pedagogía de la Historia y las Ciencias

Sociales.

Riobamba, Ecuador

ORCID:

https://orcid.org/0000-0002-9533-5107

\section{EL OCASO DE LA CIUDADANÍA INDÍGENA EN EL ECUADOR CONTEMPORANEO}

\section{THE SUNSET OF INDIGENOUS CITIZENSHIP IN CONTEMPORARY ECUADOR}

DOI:

https://doi.org/10.37135/chk.002.10.01 
Número 10 / ABRIL, 2020 (12-24)

\section{EL OCASO DE LA CIUDADANIA INDÍGENA EN EL ECUADOR CONTEMPORÁNEO}

\author{
THE SUNSET OF \\ INDIGENOUS \\ CITIZENSHIP IN \\ CONTEMPORARY \\ ECUADOR

THE SUNSET OF
INDIGENOUS
CITIZENSHIP IN
CONTEMPORARY
ECUADOR

\section{Resumen}

El artículo analiza las causas y las repercusiones de la decadencia de la ciudadanía indígena en el Ecuador contemporáneo, en contraste con las experiencias de ejercicio ciudadano, emprendidas por los indígenas antes de la constitución de 2008, desde el acercamiento etnográfico y la literatura académica crítica a la interrelación del gobierno con los pueblos indígenas. El estudio concluye que el desgaste organizativo del movimiento indígena y la influencia de un gobierno concebido en las lógicas del poder tradicional (buen patrón, filántropo y pastor) provenientes del régimen de hacienda, posibilitan la desaparición de la noción de los derechos y hacen que la democracia pierda significado. Se señala también que, en esta situación, los indígenas se convierten nuevamente en seres menesterosos de quienes ejercen los cargos de representación pública, sin mayores derechos ni protagonismo político.

Palabras clave: Movimiento indígena, ciudadanía intercultural, políticas públicas.

\section{Abstract}

This article analyzes the causes and consequences of decay of the indigenous citizenship in contemporary Ecuador, in contrast to the experiences of citizen exercise undertaken by indigenous people, before the 2008 constitution, from the ethnographic and literature academic criticism of the government's interrelation with the indigenous population. The study concludes that the organizational decay of the indigenous movement and the influence of a government conceived in the logic of traditional power (good employer, philanthropist and pastor) from the financial regime, allow the disappearance of the notion of rights, and make democracy lose its meaning. It is also pointed out that during this situation indigenous people are used again by those who exercise positions of public representation, with no rights or political prominence.

Keywords: Indigenous movement, intercultural citizenship, public policies. 


\section{INTRODUCCIÓN}

Cuando la Constitución (2008) designó al Estado ecuatoriano como intercultural y plurinacional, que reconoce los derechos colectivos, la justicia indígena, la participación ciudadana, las circunscripciones territoriales, los derechos de la naturaleza, las autonomías indígenas, la democracia comunitaria y estableció el Sumak kawsay o el buen vivir como el objetivo a alcanzar en los programas de desarrollo, parecía que por fin había llegado una nueva época, en que la discriminación étnica desaparecía por completo.

Los indígenas fueron reconocidos como ciudadanos con derechos, sus demandas eran acogidas, el Estado construido sobre la matriz colonial había sido derrotado por "las lógicas de la igualdad y de la diferencia" (Rojas 2015:23), y parecía que, por fin se construía una patria para todos. No obstante, con el correr del tiempo, las promesas de días mejores que ofreció la mencionada Constitución, no lograron concretizarse suficientemente; y los pueblos indígenas que otrora demostraron capacidad de articulación de acciones colectivas, alcanzando el reconocimiento de sus derechos y la incorporación de nuevos actores en el sistema político ( $\mathrm{Za}$ mosc 2007), paulatinamente fueron desmovilizados (Pachano 2012), perdiendo así sus derechos de ciudadanía, hasta tal punto de convertirse en individuos necesitados de las ayudas de los blanco-mestizos que gobiernan y que se autodefinen como los benefactores de la "desgraciada raza indígena” (Bonifaz 1988:445).

A tenor de esta realidad, el presente artículo pretende responder a los siguientes interrogantes: ¿Cuáles son las causas que conducen a este ocaso de la ciudadanía indígena? ¿Cuáles son las repercusiones que genera esta situación en términos de derechos y de los procesos de democratización? Las posibles respuestas a estas preguntas se pueden encontrar en el análisis de la trayectoria histórica de la lucha indígena y la interrelación del movimiento indígena con los gobiernos de turno.

\section{METODOLOGÍA}

El presente artículo de investigación se elaboró a partir del acercamiento etnográfico a la trayectoria histórica del movimiento indígena y a las visiones críticas de la interrelación de los indígenas y el gobierno en el periodo 2007 - 2017 que aparecen en la literatura académica reciente. En la ejecución del análisis se tomaron en cuenta los siguientes aspectos:

a) los procesos históricos de la reivindicación indígena,

b) la apuesta por la organización comunal,

c) la participación política de los indígenas, a través del Movimiento de Unidad Plurinacional Pachakutik - Nuevo País y el Movimiento Amauta Yuyay,

d) la relación del gobierno de Rafael Correa con las bases indígenas, y

e) la visibilización de la continuidad de las antiguas formas de dominación, procedentes del régimen de hacienda en la ejecución de las políticas públicas.

\section{RESULTADOS Y DISCUSIÓN}

Los estudios referentes a los pueblos indígenas demuestran que estos a lo largo de la vida republicana se esforzaron por construir la ciudadanía activa. Históricamente excluidos por los blanco-mestizos y por el Estado monocultural, reclamaron el acceso a la tierra, el mejoramiento de sus condiciones de vida, sus derechos a la participación política, el reconocimiento de sus lenguas, el respeto de la diversidad cultural (Rojas 2015), el derecho a la educación bilingüe, la aceptación de sus prácticas de administración de justicia (Grijalva 2012), la 
salvaguarda de sus territorios, el respeto a la naturaleza, la defensa del agua y la construcción de un Estado plurinacional e intercultural (De Sousa 2012).

En sus localidades, los indígenas desarrollaron sus propias capacidades de agencia a fin de enfrentar a las crisis económicas, políticas, sociales y culturales. Crearon y consolidaron las organizaciones comunitarias, emprendieron los programas de desarrollo, buscaron el apoyo de los aliados estratégicos, entre estos, las organizaciones de cooperación al desarrollo, la Iglesia Católica, las Iglesias Evangélicas, instituciones que proporcionaron recursos económicos y tecnológicos, con los que construyeron caminos vecinales, infraestructura educativa, servicios de agua entubada, el mejoramiento de la producción agropecuaria y la capacitación de los líderes comunitarios.

Entre las organizaciones comunitarias creadas por los indígenas, se destaca la comuna, organismo que se convirtió en ente articulador de la interrelación y negociación indígena con las instituciones estatales y otras entidades de cooperación. Si bien es cierto, la organización comunal fue reconocida por la legislación nacional, desde 1937, a través de la Ley de Régimen de Organización y de Comunas; sin embargo, por la oposición de los blanco-mestizos de los centros parroquiales y de los hacendados, esta ley solo se ejecutó después de la segunda reforma agraria, en 1973, cuando fueron creadas la mayoría de las comunas indígenas.

Contar con la comuna fue para los indígenas un paso significativo en la búsqueda de su liberación, de la dominación de los hacendados y de los blanco-mestizos que administraban las poblaciones indígenas, despóticamente. Antes de contar con la organización comunal, los indígenas dependían de los centros parroquiales. En estos lugares eran objetos de explotación, no podían tomar decisiones por sí mismos (Pallares 2000), ni tener recursos, ni establecimientos educativos donde educar a sus hijos.

La comuna se convirtió en un espacio de democratización, de resistencia y de otorgamiento de derechos. Con la organización comunal, reconocida legalmente por el gobierno, los indígenas fundaron las escuelas, posibilitando así el acceso de niñas y niños a la educación primaria y secundaria (Tuaza, 2017); obtuvieron obras de infraestructura: casas comunales, espacios deportivos, servicios de agua entubada y riego, talleres artesanales, formaron a líderes y lideresas que con el tiempo llegaron a los espacios de representación pública.

En la comuna fue posible, también, la resolución de conflictos concernientes a temas jurídicos. Si en el pasado los litigios de tierras, de familias y de cónyuges se resolvían ante el teniente político y los jueces a un costo económico alto, o los juicios no eran resueltos a brevedad; en el espacio comunitario se podían solucionar los problemas rápidamente y con beneficios para las dos partes involucradas en el pleito (García 2012).

Para la década de los noventa del siglo pasado, más allá de la organización comunal, los indígenas crearon las Organizaciones de Segundo Grado (OSG) que aglutinaban a varias comunas y asociaciones a nivel cantonal y provincial. En 1986, los dirigentes indígenas, representantes de las OSG de las distintas partes del país, fundaron la Confederación de Pueblos y Nacionalidades Indígenas del Ecuador (CONAIE).

Animados por esta organización nacional, los indígenas protagonizaron los levantamientos (1990, 1992, 1997 y 2000) que paralizaron al país. Las dos últimas movilizaciones (1997 y 2000) desataron la caída de los gobiernos de Abdalá Bucaram y Jamil Mahuad. El eslogan de las mencionadas acciones colectivas fue: "nada solo para los indios, la unidad en la diversidad" (Tuaza 2011:60). Este ideal atrajo la simpatía y el respaldo de otros sectores sociales a la lucha indígena.

En el afán de conquistar la participación política, los indígenas crearon el Movimiento de Unidad Plurinacional, Pachakutik Nuevo - País (1996), brazo político de la CONAIE (Van Cott 2005; Becker 2015), y posteriormente el Amautay Yuyay (1998), movimiento político de los indígenas evangélicos (Guamán 2006). Estos dos movimientos políticos permitieron participar a los indígenas en la contienda electoral a nivel nacional y local.

Los candidatos indígenas por Pachakutik y Amauta Yuyay, propusieron romper con las antiguas prácticas políticas, caracterizadas por la discrimi- 
nación, el clientelismo, el uso patrimonial de las instituciones estatales y la ausencia de la participación de la ciudadanía en el diseño y en la ejecución de las políticas públicas. "Gobernar consultando a las bases, gobernar obedeciendo a los verdaderos mandantes" Tuaza 2011:67), fueron las expresiones significativas con las que los candidatos se presentaron en las campañas políticas.

Las autoridades electas de estos dos movimientos políticos, especialmente de Pachakutik, una vez posesionados en los cargos de representación en los gobiernos autónomos descentralizados municipales, con alto porcentaje de población indígena como en Guamote, Chimborazo, Cotacachí en Imbabura (Ortiz 2012) y Nabón en el Azuay, promovieron la creación de los parlamentos indígenas y populares (Bebbintong \& Torres 2001). Hablaron de una democracia participativa, en la que intervienen todos los actores sociales para el diseño de la acción política, el análisis de la realidad, la elaboración de los presupuestos, el diseño de los planes de desarrollo y la toma de decisiones (Bravo 2017; Conaghan 2016).

El movimiento indígena se convirtió en un actor político decisivo en educación bilingüe, desarrollo rural, diseño institucional, el fortalecimiento de la democracia que impulsa la inclusión de grupos tradicionalmente marginalizados, así como el modelo saludable de conexiones partido-sociedad y las relaciones interétnicas (Lalander 2010).

Además, protagonizó la movilización social contra el neoliberalismo, a través de la cual se convirtió en un movimiento social en búsqueda de un liderazgo nacional (Lalander \& Ospina 2012). Aunque, la imagen de la fuerza política diferente y alternativa fue dañada (Lalander 2010), por los desaciertos en la alianza con Lucio Gutiérrez, militar que junto con el movimiento indígena provocó la caída del gobierno de Jamil Mahuad, y que, en las elecciones de 2002, llegó a la presidencia de la república. Gutiérrez, que en un principio se mostró crítico al neoliberalismo, pronto abandonó esta postura, mostrándose favorable a las políticas emanadas del consenso de Washington, situación que provocó la ruptura con Pachakutik, que formó parte de su gobierno durante los primeros seis meses.
Llegadas a la segunda década del siglo XXI, las organizaciones indígenas atraviesan las situaciones de fraccionamiento y de debilitamiento. Estos dos aspectos tienen que ver, por un lado, con el mismo desgaste del movimiento indígena, $\mathrm{y}$, por otro, con la confrontación del gobierno de Rafael Correa con la CONAIE.

Con respecto al desgaste, esto se produjo por los desaciertos en la alianza de los indígenas con $\mathrm{Lu}-$ cio Gutiérrez, tal como se ha señalado anteriormente, dado que los dirigentes pertenecientes a la Federación de Indígenas Evangélicos del Ecuador (FEINE), prefirieron continuar siendo parte del gobierno, mientras que los militantes de Pachakutik y de la CONAIE se retiraron.

Asimismo, las organizaciones comunitarias y otras de alcance nacional se sentían escasamente representadas por la CONAIE (Sánchez-Parga 2007; Tuaza 2011). Adicionalmente, en las bases del movimiento indígena existían fraccionamientos y confrontaciones entre los líderes, las organizaciones, ocasionadas por la influencia de los proyectos de desarrollo, la migración campo-ciudad, el cambio generacional de la dirigencia y casos de corrupción.

Los estudios señalan igualmente que las organizaciones indígenas como el Ecuador Runakunapak Rikcharimuy (ECUARUNARI), filial de la CONAIE y otras organizaciones campesinas e indígenas han mantenido las protestas medioambientales y el rechazo a las acciones del gobierno, pero con escasos resultados (Pachano \& Freidenberg 2016). En efecto, durante los diez años del mandato presidencial de Rafael Correa, las convocatorias del movimiento indígena a las marchas por el agua y el rechazo a la minería a gran escala en los territorios indígenas encontraron escasa respuesta de la población indígena.

Por otra parte, la decadencia de las organizaciones indígenas se explica por la influencia del gobierno de Rafael Correa que, según los estudios, se ha caracterizado por ser personalista, confrontacional, populista y tecnocrático (De la Torre 2013). Correa, pese a considerarse como la encarnación del pueblo (De la Torre 2011), el amigo, el mashi, el actor político que hace posible la "refundación de 
la patria, la segunda y definitiva independencia" (Correa 2013:20) se mostró hostil al movimiento indígena, persiguió a los dirigentes y calificó de sabotaje y terrorismo las movilizaciones convocadas por la CONAIE, judicializó la lucha social (Lalander \& Ospina 2012), y mandó apresar a los dirigentes que protagonizaron las marchas y el cierre de las vías en Zamora Chinchipe, Morona Santiago y Loja, tres provincias afectadas por la minería a cielo abierto.

Por su parte, Meléndez y Moncagatta (2017) señalan que la "figura altamente carismática y la utilización de una retórica polarizadora hicieron posible el establecimiento de una comunicación directa con las masas, debilitando de este modo las instituciones democráticas y así mantenerse en el poder" (Meléndez \& Moncagatta 2017:437), a la que hay que añadir, igualmente, la decadencia de las organizaciones de la sociedad civil, entre estas, el Frente Unitario de Trabajadores y la Unión Nacional de Educadores.

En efecto, la figura carismática de Correa no solo atraía la simpatía del pueblo, sino que se tradujo en prepotencia, porque él demarcaba la separación entre quienes estaban a su favor y quienes se convertían en sus adversarios. Dado que el movimiento indígena mantenía un discurso contestatario al régimen, en 2010 Correa despojó a la CONAIE de la dirección del Consejo de Desarrollo de los Pueblos Indígenas y de la Dirección de Educación Bilingüe Intercultural (Altmann 2014), instituciones gubernamentales que, desde la fundación, venían siendo administradas por las organizaciones indígenas.

En teoría, Correa pregonaba la participación ciudadana como el eje transversal de la acción política, pero en la práctica, estatizó y desde el poder se crearon y promocionaron las organizaciones sociales afines a su gobierno, a la vez que se fragmentaron, debilitaron y cooptaron a las organizaciones de la sociedad civil. "En su afán de debilitar a la CONAIE desempolvó del olvido a la Federación Ecuatoriana de Indios, antigua organización del Partido Comunista, que casi había desaparecido en los años ochenta y noventa" (De la Torre 2011:69).
La participación ciudadana, al convertirse en un atributo estatal limitó "las posibilidades de reconocerla como la acción libre e instantánea de la sociedad, que incluso puede aparecer como subversiva ya que no se realiza en esos ámbitos institucionales" (Pachano 2012:98). De hecho, la movilización social protagonizada por los movimientos sociales fue considerada por el régimen, actos de sabotaje y terrorismo (Correa 2012).

Los estudios señalan igualmente que Correa en el ejercicio gubernamental, fomentó el hiper-presidencialismo, con el cual deterioró la calidad de la democracia, radicalizó el esquema autoritario de poder bajo la concentración de los recursos políticos y la neutralización de los poderes fácticos (Pachano \& Freidenberg 2016; Conaghan 2016; Basabe \& Martínez 2014; Collins 2014) actos que fueron justificados con la misma constitución de 2008 que otorga mayor capacidad de maniobra al ejecutivo, en menosprecio de otros poderes del estado.

En contraste a los estudios antes mencionados, Lalander y Ospina (2012) sugieren entender el conflicto del gobierno de Rafael Correa y el movimiento indígena desde otras perspectivas. Para estos autores, la confrontación tiene que ver con el dilema intercultural, la oposición al extractivismo por parte de las organizaciones indígenas, las diferencias en cuanto a la apreciación de la movilización social, la política agraria y la política estatal orientadas a la desectorización de las organizaciones sociales.

En cuanto al dilema intercultural, los mencionados autores señalan que, en la primera campaña presidencial, Correa y el movimiento Alianza PAIS intentaron acercarse al movimiento indígena, ofreciendo la vicepresidencia a Luis Macas o a Auki Tituaña, líderes históricos, pero ellos no aceptaron, por cuanto que la CONAIE buscaba reforzar la identidad propia, colocando en segundo lugar la política de alianzas (Lalander \& Ospina 2012).

En cuanto a la política agraria, Correa respaldó la actividad agropecuaria a gran escala promovida por los agroindustriales, en menosprecio de los pequeños agricultores. Asimismo, su oferta de 
redistribuir la tierra entre quienes trabajan quedó en el olvido. Los indígenas a su vez solicitaban la redistribución de la tierra y el apoyo a la actividad agropecuaria familiar y comunitaria (Lalander \& Ospina 2012), peticiones que no fueron acogidas por el gobierno.

Con respecto a la plataforma organizativa, el gobierno de Correa buscó la desmovilización de las organizaciones sociales, aprovechando el debilitamiento que estas atravesaban. Según la versión del gobierno, las organizaciones sociales y el corporativismo serían los responsables de detener el desarrollo nacional (Dávalos 2012). En contraste, el movimiento indígena buscó el fortalecimiento de sus organizaciones, pero con escasos resultados, porque no podía competir con el gobierno que había coaptado a las bases con la entrega de obras en las comunidades.

A diferencia de las versiones anteriores, los análisis políticos que respaldan los aciertos del gobierno de Rafael Correa con respecto a los pueblos indígenas, señalan que la cuestión indígena fue importante durante su gestión (Martín 2012), porque junto con el reconocimiento del carácter plurinacional del Estado, la Constitución y las leyes sobre todo el Código de Ordenamiento Territorial, Autonomías y Descentralización (COOTAD) y la Ley de Participación Ciudadana habría posibilitado la creación de las circunscripciones territoriales indígenas, las "autonomías indígenas y la democracia comunitaria” (Ramírez 2012:177).

Asimismo, destacan que Correa promovió las políticas públicas como el bono de desarrollo humano, el bono de la vivienda, el subsidio universal del gas doméstico, la tarifa de la dignidad aplicada al consumo de la electricidad, el cuidado de las personas discapacitadas, la eliminación de barreras de acceso a la educación y a la salud, la gratuidad de la educación pública universitaria (Martín, 2012), la titularización de las tierras improductivas de propiedad estatal que favorecería a la lucha contra la desigualdad social (Ramírez 2012:130136) y que en criterios de los beneficiarios, mejoraron las condiciones de vida.

Sin embargo, estas obras fueron concebidas por el gobierno nacional y por las autoridades de los go- biernos autónomos descentralizados parroquiales, cantonales y provinciales como si fueran ayudas, por lo que los beneficiarios quedaban en deuda. Esta práctica tiene que ver con la reciprocidad andina y con las estrategias de interrelación de las autoridades blanco-mestizas e indígenas en condiciones asimétricas, provenientes del antiguo mundo de la hacienda.

En el contexto andino, según los estudios de Ferraro (2004) es importante la interrelación social en términos de reciprocidad, don y deuda. En alguna necesidad urgente, las familias indígenas acuden a otras familias a solicitar favores, ya sean en dinero o en especies agropecuarias, a fin de poder solucionar cuanto antes los problemas que atraviesan.

Esta deuda puede ser pagada en un tiempo determinado o cuando el deudor esté en capacidad de pagar. Mientras dure la deuda, los adeudados no pueden entrar en enemistad con aquellos que le otorgaron el favor. Las ayudas se pagan con gratitudes y con acciones inmediatas, de acuerdo con el requerimiento de quienes ofrecieron el auxilio.

La práctica de la reciprocidad en el pasado fue adaptada y resignificada por los dueños de las haciendas serranas. Los patrones sabían con exactitud que debían otorgar las ayudas, cuando sus súbditos indígenas huasipungueros, llamados así por vivir en un pequeño lote de tierra, propiedad de la hacienda, requerían del dinero, productos y animales para cubrir los costos de la calamidad doméstica, pasar la fiesta en honor a algún santo (Lyons 2016), en condición de priostes.

Las deudas contraídas en muchas ocasiones no podían ser pagadas y la obligación de pagar duraba toda la vida e incluso eran heredadas por los hijos (Rubio 1987). A cambio de los favores recibidos de sus amos, los indígenas tenían que trabajar gratuitamente en los predios del patrón y ser dóciles a los mandatos que este impusiera.

Aunque la voluntad del patrón era prejuiciosa, ellos no tenían el derecho a reclamar, peor aún a denunciar los atropellos ante las autoridades locales, porque muchos de ellos eran aliados con los mismos hacendados (De la Torre 1989). Obedecer, callar, hacer y agradecer fueron los verbos más comunes en la interrelación asimétrica entre patro- 
nes e indígenas (Burgos 1997).

Durante las movilizaciones indígenas de marzo de 2010, una de las funcionarias del Ministerio de Vivienda y Desarrollo Urbano les recuerda a los moradores de Pachagsi, Tixán, Chimborazo:

... compañeros, no hay necesidad de estar yendo al paro. Este gobierno ha hecho mucho por ustedes. Nadie como él les ha ayudado a ustedes. Sería el colmo salir a protestar a un gobierno amigo. Eso sería ser malagradecidos. Ustedes no han de querer ser malagradecidos ¿Verdad?, a lo que la multitud les responde, " $¡ N o$, nosotros apoyamos a nuestro presidente!". (Citado por Tuaza 2011:240)

Mostrar gratitud y no ser malagradecidos, según esta funcionaria, sería no protestar, no ir a las movilizaciones organizadas por la CONAIE, reconocer al gobierno que ha hecho mucho, el amigo autodenominado el mashi, aunque esta palabra provenga de masha, cuñada o cuñado, cuyo significado literal sería, el "intruso, ajeno y extraño a la familia y a la comunidad" (Cordero 1955:46).

Similar a la opinión de la funcionaria, Correa en la visita a la comunidad de San Guisel, Colta, el 11 de mayo de 2010, con ocasión de la entrega de 680 viviendas en ese sector, manifestó: uyaychik mashikuna, escúchenme amigos, ningún gobierno se ha preocupado de ayudarles tanto. Nosotros sí nos preocupamos por dar la ayuda. No sean kaspi umas, olvidadizos de lo que nosotros hacemos por ustedes. No necesitan salir a las calles a apoyar a esos atrasa patrias. (Correa 2013:2), aludiendo a los indígenas de la CONAIE que en esos días realizaban las marchas en las calles de Quito por la ley del agua.

Por otro lado, los funcionarios del gobierno a nivel local y quienes ostentaban los cargos de representación en los gobiernos autónomos descentralizados parroquiales, municipales y provinciales, manejaron exactamente la idea de la ayuda en el momento de ejecutar las políticas públicas. Ellos estuvieron enteramente convencidos de ayudar a los indígenas (Tuaza 2014).

En la rendición de cuentas del gobierno provincial de Chimborazo (2018), una de las autoridades ma- nifestó: “el pueblo de Chimborazo, sabrá agradecer todo el apoyo y la ayuda que hemos brindado como autoridades" (GADPCH 2018:15). Evidentemente, quienes ejercen los cargos de representación no se conciben propiamente autoridades, sino personas con espíritu altruista que desde el cargo que ostentan, ayudan y exigen gratitudes y lealtades.

Por su parte, los indígenas saben por tradición que siempre hay que ser agradecidos con los patrones y sus intermediarios (Guerrero 2010), aceptando el trabajo que ellos les impongan y ofreciéndoles regalos en las festividades especiales como el carnaval y la inauguración de las obras. Actualmente, la manera de expresar la gratitud es votando en las urnas para una reelección o respaldando al candidato propuesto por quienes están en cargos de representación.

Asimismo, en la lógica de interrelación, Correa, las autoridades locales y los indígenas fueron caracterizados por la incorporación de las viejas tácticas del poder, reforzando así la relación asimétrica entre quienes ayudan y quienes reciben los favores. Citando a Michael Foucault, se puede decir que hubo la integración de "una nueva forma de poder en base a una vieja técnica de poder que nació en las instituciones cristianas" (Foucault 1988:8), conocida como el poder pastoral.

De acuerdo a Foucault, los individuos, en virtud de su calidad religiosa han recibido un poder especial y pueden servir a otros no como príncipes, magistrados sino como pastores, que buscan asegurar la salvación, están dispuestos a sacrificarse por la vida y por la redención del rebaño, se preocupan por cada individuo particular durante toda su vida, conocen el pensamiento interior de la gente, explotan sus almas y hacen revelar sus secretos más íntimos (Foucault 1988:8-11). Esta concepción del poder hace que quienes reciben los favores, escasamente cuestionen a sus autoridades, son simplemente fieles u ovejas que esperan ser guiadas, ayudadas y protegidas por sus pastores.

El conocimiento del poder pastoral y su funcionamiento no son ajenos a Correa ni a las autoridades locales. Correa, durante su niñez, la adolescencia y los primeros años de juventud fue formado en 
los establecimientos educativos católicos. Tras concluir los primeros años de estudios universitarios, trabajó en la misión salesiana de Zumbahua, en calidad de voluntario (Almeida \& López 2017).

Las autoridades y líderes locales igualmente poseen la influencia del poder pastoral. Algunos en el pasado fueron formados en el ámbito eclesial católico y evangélico. Esto hace que, a más de actuar en calidad de buenos patrones y personas filantrópicas, aparezcan como buenos pastores que guían a la grey hacia el paraíso terrenal, llamado el sumak kawsay.

\section{CONCLUSIONES}

El análisis demuestra que los indígenas antes de la constitución de 2008 mantuvieron la acción colectiva significativa en pos de la reivindicación de sus derechos, desarrollaron sus propias capacidades de agencia a la hora de resolver sus conflictos, crearon y consolidaron la organización comunitaria, buscaron el apoyo de los aliados estratégicos, protagonizaron los levantamientos, fundaron los movimientos políticos, a través de los cuales alcanzaron la participación política y apostaron por un proceso serio de democratización y su posicionamiento en la escena política nacional en condición de ciudadanos.

Igualmente, el reconocimiento del Estado ecuatoriano como intercultural y plurinacional, la legitimidad de la justicia indígena, los derechos colectivos y los derechos de la naturaleza son consecuencia de la larga lucha social de los pueblos indígenas, efectuada antes de la elaboración de la constitución de 2008.

En los procesos de articulación de la acción colectiva de los pueblos indígenas, anterior a 2008, se puede evidenciar la toma de conciencia, en cuanto a los derechos a la tierra, a la libertad, a la educación, a la salud, al acceso a recursos económicos y tecnológicos, y a la participación política en condición de igualdad. Los indígenas establecieron las negociaciones con el Estado, en virtud de derechos y en condiciones de ciudadanos. De este modo intentaron romper con el pasado colonial hacendatario (Quijano 2005), caracterizado por la discriminación y el sometimiento. No obstante, aparece el desgaste al interior de las organizaciones y comunidades por las divisiones internas, la multiplicación de los proyectos de desarrollo, la migración campo-ciudad y el cambio generacional de la dirigencia. Esta situación se radicaliza por la influencia de los gobiernos autoritarios, paradójicamente concebidos como buenos patrones, filántropos y pastores. Las llamadas ayudas ofrecidas por estos gobernantes hacen que desaparezca la conciencia ciudadana, el ideal de lucha por los derechos, la articulación de la acción colectiva y la apuesta por los procesos serios de democratización.

Bajo la potestad de los gobernantes patrones, filántropos y pastores, los indígenas dejan de ser ciudadanos. Se convierten nuevamente en personas subalternas, pobres, necesitados de la ayuda. A cambio de esto, se quedan con la deuda de agradecer, en el momento en que sus benefactores requieran ser respaldados.

En un contexto político y social, donde no existe la ciudadanía activa, los gobernantes reproducen las antiguas tácticas del ejercicio del poder heredado del pasado colonial hacendatario, traducido en la imagen del buen patrón que, aunque tenga actitudes prepotentes, es capaz de otorgarles la ayuda, como un padre rico enfurecido con sus hijos, pero que tiene el corazón misericordioso, capaz de sentir compasión por los que suplican clemencia.

En situaciones donde los ciudadanos se encuentran desmovilizados, ellos no tienen ni voz ni voto. Otros toman las decisiones por ellos. La única opción que tienen es la de acudir a los talleres de capacitaciones promocionadas por los llamados benefactores y a las concentraciones masivas obligadas. De acuerdo la Constitución de 2008, es imprescindible que la planificación estatal cuente con la participación de la sociedad civil, y en el Artículo 57, numeral 7 señala que: "los pueblos indígenas tienen derecho a la consulta previa, libre e informada, dentro de un plazo razonable, sobre planes y programas de prospección, explotación y comercialización de recursos no renovables que se encuentren en sus tierras y que puedan afectarles 
ambiental o culturalmente"; sin embargo, durante el gobierno de Correa, esto se redujo "a escuchar la socialización de los proyectos elaborados por los técnicos de la Secretaria Nacional de Planificación y a los plebiscitos que legitiman el liderazgo del presidente" (De la Torre 2011:68).

Cuando las organizaciones sociales están debilitadas y los ciudadanos acuden a sus gobernantes a solicitar ayudas y estos últimos procesan las demandas, convencidos de ser benefactores, pastores dotados de carisma mesiánica que personifican al pueblo y se creen ser elegidos para marcar un antes y un después en el destino de sus pueblos, no es posible la democracia, especialmente el requisito de la rendición de cuentas, porque el régimen democrático "implica exigir de los funcionarios públicos la resolución de problemas, el cumplimiento de promesas electorales, el respeto a los derechos ciudadanos" (Levine \& Molina 2011:103) y la transparencia en el manejo económico.

Por más que se hable de la participación ciudadana, los derechos constitucionales a favor de los pueblos y nacionalidades, la vigencia del estado de derecho, la democracia participativa y comunitaria y las elecciones; resignificados con las viejas tácticas del poder a las que Foucault denominó el poder pastoral (Foucault 1988), escasamente se puede cuestionar la autoridad gubernamental. Los ciudadanos son simplemente fieles que esperan ser guiados, atendidos y protegidos por sus pastores.

En las dinámicas de interrelación pastor y grey, aparecen verdades absolutas, tradiciones inamovibles, las cuales la grey asume sin cuestionamientos ni protestas, así, no es posible la democracia, no hay opción al reclamo, a la deliberación en el manejo del poder ni a la toma de decisiones concernientes a los asuntos que competen a todos los actores de la sociedad. Además, para quienes ejercen el poder, el ejercicio ciudadano y el reclamo de los derechos resultan hostiles (Peruzzotti 2008), por los que buscarán debilitar a la ciudadanía cuanto antes.

Sin la capacidad de reclamo, sin rendición de cuentas, con una ciudadanía desactivada, los gobiernos mesiánicos, filántropos, buenos patrones y pastores ocultan en sus aparentes actos de cari- dad, no solo el propósito de capitalizar gratitudes y respaldos electorales, sino que corren el riesgo de caer en actos de corrupción.

En efecto, en estos últimos años, los medios de comunicación y aun los antiguos colaboradores del régimen de Correa, ahora miembros del gobierno de Lenín Moreno, señalan los casos de corrupción en las instituciones gubernamentales, especialmente relacionados con los sectores estratégicos de la economía nacional (Vicuña 2018).

Sin ciudadanía y con presencia de gobiernos mesiánicos, populistas, buenos patrones y pastores, parafraseando a Dani Rodrik (2018), se puede decir que se pone de manifiesto la amenaza a la democracia, en la medida en que esta se convierte en "una forma de política autoritaria que tiene elecciones populares, pero poco respeto al imperio de la ley y a los derechos de las minorías". Una democracia que a decir de Windy Brown (2016) se convierte en un significado vacío, capturado por el neoliberalismo.

\section{REFERENCIAS BIBLIOGRÁFICAS}

Almeida, M. \& López, A. (2017). El séptimo Rafael. Quito: Editorial APERIMUS.

Altmann, P. (2014). Una breve historia de las organizaciones del movimiento indígena del Ecuador. Arqueología ecuatoriana: cuadernos de investigación, (12), 1 -27. Recuperado de https://revistas.arqueo-ecuatoriana. ec/es/cuadernos-de-investigacion/cuadernos-de-investigacion-12/295-una-breve-historia-de-las-organizaciones-del-movimiento-indigena-del-ecuador

Basabe-Serrano, S. \& Martínez, J. (2014). Ecuador: Cada vez menos democracia, cada vez más autoritarismo... con elecciones. Revista de Ciencia Politica, 34(1), 145 - 170.

Bebbington, A. \& Torres, V. (2001). Capital social en los Andes. Quito, Ecuador: Abya Yala.

Becker, M. (2015). ¡Pachakutik!: movimientos indígenas, proyectos políticos y disputas 
electorales en el Ecuador. Quito, Ecuador: FLACSO y Abya Yala.

Bonifaz, E. (1988). Comportamiento. En Malo, C. (Compilador), Pensamiento indigenista del Ecuador, (pp. 443-503). Quito, Ecuador: Corporación Editora Nacional.

Bravo, C. (2017). Chimborazo en el ojo del huracán: el movimiento indígena en la coyuntura de la Revolución Ciudadana (2007 2015) (tesis de maestría), FLACSO, Quito, Ecuador.

Brown, W. (2016). El pueblo sin atributos: La secreta revolución del neoliberalismo. Barcelona, España: Malpaso.

Burgos, H. (1997). Relaciones interétnicas en Riobamba. Quito, Ecuador: Corporación Editora Nacional.

Collins, J. (2014). New Left Experiences in Bolivia and Ecuador and the Challenge to Theories of Populism. Journal of Latin American Studies, 46(1), 59 - 86.

Conaghan, C. (2016). Delegative Democracy Revisited Ecuador Under Correa. Journal of Democracy, 27(3), 109 - 118.

Constitución de la República del Ecuador (2008). Recuperado de https://www.oas.org/juridico/pdfs/mesicic4_ecu_const.pdf.

Cordero, L. (1955). Diccionario quichua - español. Quito, Ecuador: Casa de la Cultura Ecuatoriana.

Correa, R. (22 de diciembre de 2012). Nosotros ya actualizamos las leyes contra el terrorismo. Ecuador inmediato. Recuperado de http://www.ecuadorinmediato.com/index. php? module $=$ Noticias $\&$ func $=$ news_user view\&id=187980\&umt=jefe_estado_nosotros_ya_actualizamos_leyes_contra_terrorismo

Correa, R. (5 de febrero de 2013), El desarrollo de la minería. Diario El Universo. Recuperado de https://www.eluniverso. com/2013/02/05/1/1366/problemas-mineria.html
Dávalos, P. (2012). Las clases medias ecuatorianas y el Ángel de la historia. En Mantilla, S. y Mejía, S. (Eds), Rafael Correa: balance de la revolución ciudadana (pp. 97 - 123). Quito, Ecuador: Editorial Planeta.

De la Torre, P. (1989). Patrones y conciertos: una hacienda serrana, 1905 - 1929. Quito, Ecuador: Corporación Editora Nacional.

De la Torre, C. (2011). Las tensiones no resueltas entre el populismo y la democracia procedimental. Revista de Ciencias Sociales de la Universidad Católica de Uruguay, 2(2), $63-79$.

De la Torre, C. (2013). Latin America's Authoritarian Drift: Technocratic Populism in Ecuador. Journal of Democracy, 24(3), 33 - 46.

De Sousa, B. (2012). Cuando los excluidos tienen derecho: justicia indígena, plurinacionalidad e interculturalidad. En B. De Sousa y A. Grijalva (Eds), Justicia indígena, plurinacionalidad e intercuturalidad en Ecuador (pp. 13 - 50). Quito, Ecuador: Fundación Rosa Luxemburg.

Ferraro, E. (2004). Reciprocidad, don y deuda. Formas y relaciones de intercambio en los Andes de Ecuador: la comunidad de Pesillo. Quito, Ecuador: Abya Yala.

Foucault, M. (1988). El sujeto y el poder. Revista Mexicana de Sociología, 50(3), 3 - 20.

García, F. (2012). No se aloquen, no vayan a carrera de caballo, vayan a carrera de burro: comunidades Chimborazo y Chiboleo. En B. De Sousa y A. Grijalva (Eds), Justicia indígena, plurinacionalidad e intercuturalidad en Ecuador (pp. 501 - 549). Quito, Ecuador: Fundación Rosa Luxemburg.

Gobierno Autónomo Descentralizado de la Provincia de Chimborazo. (2018). Rendición de cuentas 2018. Riobamba: GAD.

Grijalva, A. (2012). Del presente se inventa el futuro: justicias indígenas y Estado en Ecuador. En B. De Sousa y A. Grijalva (Eds), Justicia indígena, plurinacionalidad e inter- 
cuturalidad en Ecuador (pp. 51 - 76). Quito, Ecuador: Fundación Rosa Luxemburg.

Guamán, J. (2006). FEINE, la organización de los indígenas evangélicos en el Ecuador. Quito, Ecuador: Universidad Andina Simón Bolívar, Abya Yala y Corporación Editora Nacional.

Guerrero, A. (2010). Administración de poblaciones, ventriloquia y transescritura. Quito, Ecuador: FLACSO e Instituto de Estudios Peruanos.

Lalander, R. (2010). Retorno de los runakuna. Cotacachi y Otavalo. Quito: Abya Yala.

Lalander, R. \& Ospina, P. (2012). Movimiento indígena y revolución ciudadana en Ecuador. Cuestiones Políticas, 28(48), 13 - 50.

Levine, D. \& Molina, E. (2011). Calidad de la democracia: fortalezas y debilidades en América Latina, Revista Latinoamericana de Política Comparada, (5), 95 - 123.

Lyons, B. (2016). Sociedad, historia e interculturalidad en Chimborazo. Quito, Ecuador: Abya Yala y Wayne State.

Martín, F. (2012). El desempeño de la economía ecuatoriana durante el gobierno del economista Rafael Correa. En S. Mantilla y S. Mejía (Coordinadores), Rafael Correa: balance de la revolución ciudadana (pp. 237 - 266). Quito, Ecuador: Planeta.

Meléndez, C. \& Moncagatta, P. (2017). Ecuador una década de correísmo. Revista de Ciencia Política, 37(2), 413 - 447.

Ortiz, S. (2012). ¿Comuneros kichwas o ciudadanos ecuatorianos?: la ciudadanía étnica y los derechos políticos de los indígenas de Otavalo y Cotacachi (1990 2009). Quito, Ecuador: FLACSO.

Pachano, S. \& Freidenberg, F. (2016). El sistema político ecuatoriano. Quito, Ecuador: FLACSO.

Pachano, S. (2012). Estado actual y futuro de la democracia en Ecuador. En A. Dargatz y
M. Zuazo (Eds), Democracias en transformación: ¿Qué hay de nuevo en los nuevos Estados andinos? (pp. 81 - 102). La Paz, Bolivia: Friedrich Ebert Stiftung.

Pallares, A. (2000). Bajo la sombra de Yaruquíes: Cacha se reinventa. En A. Guerrero (Ed), Etnicidades (pp. 267 - 313). Quito, Ecuador: FLACSO.

Peruzzotti, E. (2008). Populismo y representación democrática. En C. De la Torre y E. Peruzzotti (Eds), El retorno del pueblo. El populismo y nuevas democracias en América Latina (pp. 97 - 125). Quito, Ecuador: FLACSO.

Quijano, A. (2005). El movimiento indígena, la democracia y las cuestiones pendientes en América Latina. Polis, (10), 1-23. Recuperado de https://journals.openedition.org/polis/7500

Ramírez, F. (2012). Perspectivas del proceso de democratización en Ecuador. Cambio político e inclusión social (2005 - 2010). En A. Dargatz y M. Zuazo (Eds), Democracias en transformación: ¿Qué hay de nuevo en los nuevos Estados andinos? (pp. 103 - 154). La Paz, Bolivia: Friedrich Ebert Stiftung.

Rodrik, D. (2018). Las dos amenazas contra la democracia liberal. Revista Nueva Sociedad. Recuperado de http://nuso.org/articulo/ las-dos-amenazas-contra-la-democracia-liberal/

Rojas, C. (2015). Ciudadanía indígena: luchas históricas por la igualdad y la diferencia colonial en Bolivia. Cuadernos de Antropología Social, (42), 19 - 34.

Rubio, G. (1987). Los indios ecuatorianos: evolución histórica y políticas indigenistas. Quito, Ecuador: Corporación Editora Nacional.

Sánchez-Parga, J. (2007). El movimiento indígena ecuatoriano: la larga ruta de la comunidad al partido. Quito, Ecuador: CAAP.

Tuaza, L. (2011). Runakunaka ashka shaikuska shinami rikurinkuna, ña mana tandanaku- 
nata munankunachu: crisis del movimiento indígena ecuatoriano. Quito, Ecuador: FLACSO.

Tuaza, L. (2014). La continuidad de los discursos y prácticas de la hacienda en el contexto de la cooperación. Revista de Antropología Social, (23), $117-135$.

Tuaza, L. (2017). La construcción de la comunidad desde los imaginarios indígenas. Riobamba, Ecuador: UNACH.

Van Cott, D. (2005). From Movements to Parties in Latin America. Cambridge: University Press.

Vicuña, M. (14 de abril de 2018). En gobierno de Correa campeaba la corrupción. Revista Vistazo. Recuperado de https://www.vistazo.com/seccion/pais/politica-nacional/vicuna-en-gobierno-de-correa-campeaba-la-corrupcion

Zamosc, L. (2007). The Indian Movement and Political Democracy in Ecuador. Latin American Politics and Society, 49(3), 1 - 34. 